\title{
FAKTOR - FAKTOR YANG MENENTUKAN PENINGKATAN BISNIS RITEL DI INDONESIA
}

\author{
Rudy Santosa Sudirga \\ Manajemen, Universitas Bunda Mulia \\ Alamat surel: rudysudirga@yahoo.com
}

\begin{abstract}
This factor analysis research is based on the increase spending factors of household consumer product, food and beverage consumer product, consumer electronic product, increase of Indonesian population, increase of retail store in Indonesia. The most dominant factor for the improvement of retail business in Indonesia is the increasing of food and beverage product expenditure with a compound annual growth rate of 10.5\% in 2016 - 2020. The second factor is an improvement business in consumer electronics product spending with a growth rate of 9.7\% in 2016-2020. The third factor is an increase in the Indonesian population by $1.3 \%$ growth annually.
\end{abstract}

Keywords: food - beverage products, electronics, Indonesian population

\begin{abstract}
Abstrak
Penelitian dengan metode analisis faktor ini didasarkan pada faktor-faktor: peningkatan produk konsumen rumah tangga, peningkatan produk konsumen makanan dan minuman, peningkatan produk konsumen elektronik, peningkatan populasi Indonesia, peningkatan toko ritel di Indonesia. Faktor yang paling dominan bagi peningkatan bisnis ritel di Indonesia adalah faktor peningkatan belanja produk konsumen makanan dan minuman dengan tingkat pertumbuhan tahunan gabungan sebesar 10,5\% pada tahun 2016 2020. Faktor kedua bagi peningkatan bisnis ritel di Indonesia adalah faktor peningkatan belanja produk konsumen elektronik dengan tingkat pertumbuhan sebesar 9,7\% pada tahun 2016 - 2020. Faktor ketiga bagi peningkatan bisnis ritel di Indonesia adalah peningkatan populasi Indonesia dengan pertumbuhan $1,3 \%$ setiap tahun.
\end{abstract}

Kata kunci: produk makanan - minuman, elektronik, populasi Indonesia

\section{PENDAHULUAN}

\section{${ }^{1}$ Latar Belakang Penelitian}

Meningkatnya persaingan di bisnis ritel dengan maraknya pasar swalayan dan mini swalayan baik lokal maupun asing membawa dampak yang baik bagi peningkatan kesempatan kerja di Indonesia. Agar bisnis ritel di Indonesia tetap dapat berkembang dengan baik, maka penelitian ini mendalami faktor-faktor yang menentukan peningkatan bisnis ritel di Indonesia. Penelitian ini secara khusus bertujuan untuk mengetahui faktor-faktor yang menentukan peningkatan dan perkembangan bisnis ritel di Indonesia. Demi mencapai tujuan ini maka terlebih dahulu di kemukakan perkembangan makro

\footnotetext{
1 "Terimakasih kepada Universitas Bunda Mulia, Direktorat P3M UBM atas terselenggaranya penelitian ini dengan pendanaan dari Direktorat P3M UBM"
}

ekonomi di Indonesia, struktur industri ritel, analisis perkembangan industri bisnis ritel, investasi modal, industri ritel global, dan analisis beberapa bisnis ritel hipermarket yang ada di Indonesia.

\section{TINJAUAN PUSTAKA}

Menurut DeHerder (2011:215), "Globalisasi ekonomi telah membawa perubahan dalam konsumerisme konsumen negara tersebut dengan konsumen menjadi lebih sadar akan nilai kekuatan uang dan daya beli. Ekonomi negara dan konsumen menjadi lebih baik dan nyata ketimbang di generasi sebelumnya".

Menurut Berman (2013:211), "Beberapa faktor lingkungan yang memengaruhi perilaku sesorang dan perilaku belanja, di antaranya adalah: keadaan ekonomi, tingkat inflasi, infrastruktur tempat orang berbelanja, seperti kemacetan lalu lintas, tingkat kejahatan, dan perang harga di 
bisnis ritel. Selain itu juga memengaruhi pengusaha dan pelaku ritel, yaitu dengan munculnya format ritel baru, sedangkan untuk masyarakat akan lebih banyak orang yang bekerja di rumah, peraturan pemerintah dan masyarakat mengenai jam belanja, perlindungan konsumen, serta perkembangan nilai dan norma sosial. "Meskipun semua elemen ini mungkin belum berdampak pada pembelanja tertentu, hal itu memengaruhi pasar sasaran ritel secara keseluruhan."

Menurut Levy (2013:142),

"Empat karakteristik peritel yang telah berhasil memanfaatkan peluang pertumbuhan internasional adalah: (1) keunggulan kompetitif berkelanjutan secara global, (2) kemampuan beradaptasi, (3) budaya global, dan (4) sumber daya keuangan." Oleh karena itu, Wal-Mart dan Carrefour berhasil di pasar internasional, karena harga memegang peranan penting dalam pengambilan keputusan konsumen, dan infrastruktur distribusi yang tersedia di Wal-Mart dan Carrefour memungkinkan perusahaan-perusahaan ini mengeksploitasi kemampuan logistik mereka."

Menurut Diamond (2014:138139), "Perspektif masa depan industri ritel, yang siap meledak dan menyajikan peluang besar atau siklus pertumbuhan baru ke pasaran ritel dunia didasarkan pada skenario makro ekonomi, menganalisis kecenderungan konsumen dan konsumsi, memahami struktur industri ritel, dan menganalisis penyebab masalah yang progresif. Untuk bisnis di industri ritel faktor terpenting adalah pertumbuhan primer, arus investasi modal yang masuk di industri ritel, dan pertumbuhan global industri ritel."

Menurut Goworek (2015:125), "Kontributor utama industri ritel adalah penjualan dan belanja konsumen untuk produk makanan dan minuman. Produk makanan dan minuman yang menjadi pendorong utama belanja ritel di seluruh dunia juga telah terlihat secara nyata pertumbuhannya, yaitu dengan masuknya berbagai toko ritel asing ke suatu negara secara global, dan juga masuknya rantai industri makanan cepat saji ke negara-negara berkembang."
Menurut Diamond (2014:138-139), jurnal Ashis Mishra, Javeed Ansari (2013), dan beberapa jurnal pada penelitian terdahulu, antara lain Eunah Yoh, LuAnn R. Gaskill, (1998), Lisa Maharajh, Jeanne Heitmeyer (2006), Polly Chan, Carol Finnegan, Brenda Sternquist (2011), Wantao Yu, Ramakrishnan Ramanathan (2012), dan dari pertemuan awal dengan para pimpinan hipermarket di Jakarta, di kemukakan bahwa faktor-faktor yang memengaruhi bisnis ritel adalah: 1) peningkatan produk konsumen rumah tangga, 2) peningkatan produk konsumen makanan dan minuman, 3) peningkatan produk konsumen elektronik, 4) peningkatan populasi, 5) peningkatan jumlah toko ritel.

\section{METODE PENELITIAN}

Dalam melakukan pengumpulan data penelitian yang diperlukan, penulis melakukan pertemuan dengan beberapa direktur pemasaran, manajer gerai dan manajer pemasaran, keuangan dan operasi distribusi, dan penulis batasi untuk geraigerai Carrefour, Giant, Hypermart, Lotte. Penulis membagikan pertanyaan kuesioner penelitian kuantitatif kepada para pimpinan hipermarket di Jakarta, Bandung, Semarang, Surabaya, Medan, Ujung Pandang, dan Palembang.

Cara penelitian dan pengumpulan jawaban dari pertanyaan yang dilakukan penulis adalah dengan langsung menemui para pimpinan pasar swalayan tersebut atau menggunakan surel, sehingga terjadi interaksi jawaban secara lengkap.

Pertanyaan-pertanyaan untuk penelitian kuantitatif (analisis faktor) didasarkan pada beberapa acuan, yaitu kuesioner yang sesuai dengan kata kunci dan semua peubah pada tinjauan pustaka di atas, yaitu:

1) Apakah peningkatan bisnis ritel disebabkan oleh peningkatan produk konsumen rumah tangga,

2) Apakah peningkatan bisnis ritel disebabkan oleh peningkatan produk konsumen makanan dan minuman,

3) Apakah peningkatan bisnis ritel disebabkan oleh peningkatan produk konsumen elektronik, 
4) Apakah peningkatan bisnis ritel disebabkan oleh peningkatan populasi Indonesia,

5) Apakah peningkatan bisnis ritel disebabkan oleh peningkatan toko ritel di Indonesia.

Menurut Wijaya, T (2013:10), dan Sekaran (2017), asumsi dasar yang harus dipenuhi dalam analisis SEM (Structural Equation Modeling) adalah jumlah sampel yang memenuhi kaidah analisis. Dalam hal penelitian kuantitatif ini, penulis mengambil sampel sebanyak 150 sampel dari hipermarket yang ada di Jakarta, Bandung, Semarang, Surabaya, Medan, Ujung Pandang, dan Palembang.

Menurut Aaker (2007:561-563), analisis faktor adalah teknik yang sesuai untuk mengidentifikasi peubah atau faktor yang memiliki pola hubungan tertentu dalam sebuah kelompok peubah. Tujuannya adalah untuk mencari cara menyingkat informasi yang terdapat dalam beberapa peubah asal menjadi serangkaian peubah yang lebih kecil (faktor) dengan meminimalkan kehilangan informasi.

Pengambilan data yang dilakukan penulis adalah dengan membagikan kuesioner dengan bertemu langsung atau melalui surel, dan dilengkapi dengan sejumlah pertanyaan terbuka. Pengambilan sampel yang dilakukan oleh penulis adalah dengan teknik sampling bertingkat proporsional.

Untuk penelitian kuantitatif, penulis mengolah data penelitian dengan Structural Equation Modeling with IBM SPSS Amos version 23. Menurut Wijaya, T (2013:6 - 8), tujuan utama dari analisis SEM adalah menguji kesesuaian suatu model yaitu kesesuaian model teoritik dengan data empiris. Kriteria uji kebaikan suai (Goodness of Fit) dalam Structural Equation Modeling adalah sebagai berikut:

Tabel 1. Goodness of Fit

\begin{tabular}{|c|c|}
\hline Kriteria Indeks Ukuran & Nilai Acuan \\
\hline Chi-Square & Sekecil mungkin \\
\hline -value & $\geq 0.05$ \\
\hline CMIN/df (Normed Chi Square) & $\leq 2.00$ \\
\hline RMSEA (Root Mean Square Error of Approximation) & $\leq 0.08$ \\
\hline GFI (Goodness of Fit Index) & Mendekati 1 \\
\hline AGFI ( Adjusted GFI) & Mendekati 1 \\
\hline TLI (Tucker Lewis Index) & Mendekati 1 \\
\hline CFI (Comparative Fit Index) & Mendekati 1 \\
\hline
\end{tabular}

Sumber: Wijaya, T (2013:6 - 8)

Penjelasan dari masing-masing kriteria Goodness of Fit adalah sebagai berikut:

1. Chi Square $\left(\chi^{2}\right)$

Alat uji fundamental untuk mengukur overall fit adalah likelihood ratio chi square statistic. Model dikategorikan baik jika mempunyai chi square $=0$ berarti tidak ada perbedaan. Tingkat signifikan penerimaan yang direkomendasikan adalah apabila $p$ value $\geq 0.05$ yang berarti data matriks sebenarnya dengan matriks yang diprediksi tidak berbeda secara statistik.
2. CMIN/df (Normed Chi Square) CMIN/df adalah ukuran yang diperoleh dari nilai chi square dibagi dengan $\mathrm{df}$ (degree of freedom). Nilai yang direkomendasikan untuk menerima kesesuaian sebuah model adalah nilai CMIN/df yang lebih kecil atau sama dengan 2.00.

3. RMSEA (Root Mean Square Error of Approximation)

Nilai RMSEA menunjukkan uji kebaikan suai (Goodness of Fit) yang diharapkan bila model diestimasikan dalam populasi. Nilai 
RMSEA yang $\leq 0.08$ merupakan indeks untuk dapat diterimanya model yang menunjukkan sebuah close fit dari model itu didasarkan degree of freedom. RMSEA merupakan indeks pengukuran yang tidak dipengaruhi oleh besarnya sampel sehingga biasanya indeks ini digunakan untuk mengukur kesesuaian model pada jumlah sampel besar.

4. GFI (Goodness of Fit Index)

Digunakan untuk menghitung proporsi tertimbang dari varians dalam matriks kovarians sampel yang dijelaskan oleh matriks kovarians populasi yang terestimasikan. Indeks ini mencerminkan tingkat kesesuaian model secara keseluruhan yang dihitung dari residual kuadrat model yang diprediksi dibandingkan dengan data yang sebenarnya. Nilai Goodness of Fit Index biasanya dari 0 sampai 1 . Nilai yang lebih baik mendekati 1 mengindikasikan model yang diuji memiliki kesesuaian yang baik. Nilai GFI dikatakan baik jika $\geq$ 0.90 .

5. AGFI (Adjusted GFI)

AGFI merupakan pengembangan dari GFI yang disesuaikan dengan degree of freedom yang tersedia untuk menguji diterima atau tidak diterimanya model. Tingkat penerimaan yang direkomendasikan adalah bila mempunyai nilai $\geq 0.90$.

6. TLI (Tucker Lewis Index)

TLI adalah sebuah alternatif incremental fit index yang membandingkan sebuah model yang diuji terhadap sebuah baseline model. Nilai yang direkomendasikan sebagai acuan untuk diterimanya sebuah model adalah $\geq 0.90$ dan nilai yang mendekati 1 menunjukkan a very good fit. TLI merupakan index fit yang kurang dipengaruhi oleh ukuran sampel.

7. CFI (Comparative Fit Index)

CFI juga dikenal sebagai Bentler Comparative Index. CFI merupakan indeks kesesuaian incremental yang juga membandingkan model yang diuji dengan null model. Indeks ini dikatakan baik untuk mengukur kesesuaian sebuah model karena tidak dipengaruhi oleh ukuran sampel. (Hair et. al., 2010). Indeks yang mengindikasikan bahwa model yang diuji memiliki kesesuaian yang baik adalah apabila nilai $\mathrm{CFI} \geq 0.90$.

Menurut Hair, Black, Babin, Anderson (2010:105), secara umum, analisis faktor digunakan untuk menguji kecukupan hubungan antara peubah di mana matriks identitas berisikan diagonal matriks dengan nilai Eigenvalue $>1$. 


\section{HASIL DAN LUARAN YANG DICAPAI}

Hasil output SEM adalah sebagai berikut:

\section{ANALISIS FAKTOR}

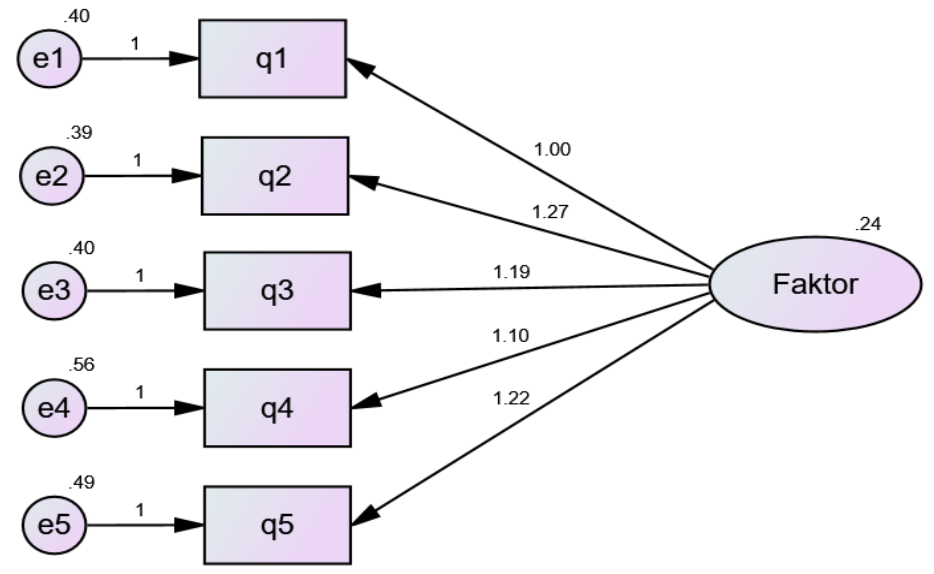

\section{Notes for Model (Default model)}

Goodness of Fit :

Chi Square: 8.495

Prob : .131

RMSEA : .068

Computation of degrees of freedom (Default model)

Number of distinct sample moments: $\quad 15$

Number of distinct parameters to be estimated: 10

Degrees of freedom (15 - 10): 5

Result (Default model)

Minimum was achieved

Chi-square $=8.495$

Degrees of freedom $=5$

Probability level $=.131$

Sumber: Pengolahan SEM dengan IBM SPSS Amos versi 23

Gambar 1. Analisis Faktor $(\mathrm{n}=150)$ 
Tabel 2. Hasil SEM $(n=150)$

\begin{tabular}{|c|c|c|c|c|c|}
\hline & Estimate & S.E. & C.R. & $\mathrm{P}$ & Label \\
\hline q1 <--- $\quad$ Faktor & 1.000 & & & & \\
\hline q2<--- Faktor & 1.268 & 208 & 6.083 & $* * *$ & par_1 \\
\hline q3<--- Faktor & 1.193 & .196 & 6.076 & $* * *$ & par_2 \\
\hline q4 <--- Faktor & 1.098 & .197 & 5.581 & $* * *$ & par_3 \\
\hline q5 <--- Faktor & 1.216 & .212 & 5.739 & $* * *$ & par_4 \\
\hline & Estimate & & & & \\
\hline q1 <--- Faktor & .614 & & & & \\
\hline $\mathrm{q} 2<---$ Faktor & .708 & & & & \\
\hline q3<--- Faktor & .680 & & & & \\
\hline q4<--- Faktor & .586 & & & & \\
\hline q5 <--- Faktor & .648 & & & & \\
\hline
\end{tabular}

CMIN

\begin{tabular}{|l|rrrrr|}
\hline Model & NPAR & CMIN & DF & P & CMIN/DF \\
\hline Default model & 10 & 8.495 & 5 & .131 & 1.699 \\
Saturated model & 15 & .000 & 0 & & \\
Independence model & 5 & 187.982 & 10 & .000 & 18.798 \\
\hline
\end{tabular}

RMR, GFI

\begin{tabular}{|l|rrrr|}
\hline Model & RMR & GFI & AGFI & PGFI \\
\hline Default model & .029 & .978 & .933 & .326 \\
Saturated model & .000 & 1.000 & & \\
Independence model & .265 & .584 & .375 & .389 \\
\hline
\end{tabular}

RMSEA

\begin{tabular}{|l|rrrr|}
\hline Model & RMSEA & LO 90 & HI 90 & PCLOSE \\
\hline Default model & .068 & .000 & .145 & .289 \\
Independence model & .346 & .303 & .390 & .000 \\
\hline
\end{tabular}

Sumber: Hasil Pengolahan SEM dengan IBM SPSS Amos versi 23

Menurut Wijaya, T (2013:50 - 51), model kesesuaian secara keseluruhan (overall fit) dapat dilihat dari nilai probabilitas sebesar $0.131>0.000$ yang berarti model dalam contoh ini sudah sesuai (sesuai antara model teoritis dengan model empiris). Pada Tabel 5.1, nilai bobot regresi menunjukkan bahwa nilai nadir (critical ratio), yang lebih besar dari dua kali standar kesalahan (standard error) yang berarti semua butir pada penelitian sahih terhadap setiap peubah penelitian secara konvergen. Contoh, peubah q2, Critical Ratio $=6.083>$ $2 \times 0.208$ (standar error), demikian seterusnya untuk peubah lainnya.

Sesuai Tabel 4.2, model dikategorikan baik jika mempunyai ChiSquare sekecil mungkin (8.495), dengan tingkat signifikan penerimaan yang direkomendasikan adalah apabila $\mathrm{p} \geq 0.05(\mathrm{p}$ $=0.131>0.05$ ), yang berarti data matriks sebenarnya dengan matriks yang diprediksi tidak berbeda secara statistik.

CMIN/df (Normed Chi Square), adalah ukuran yang diperoleh dari nilai chi square dibagi dengan df (degree of freedom). Nilai yang direkomendasikan untuk menerima kesesuaian sebuah model adalah nilai $\mathrm{CMIN} / \mathrm{df} \leq 2.00 \quad(\mathrm{CMIN} / \mathrm{df}$ (dengan degrees of freedom $=5$, Normed Chi Square $=8.495 / 5=1.699<2.00$ ).

Sesuai Tabel 5.1, RMSEA $=0.068$, nilai RMSEA menunjukkan Goodness of Fit yang diharapkan bila model diestimasikan dalam populasi. Nilai RMSEA yang $\leq 0.08$ merupakan indeks untuk dapat diterimanya 
model yang menunjukkan sebuah close fit dari model itu didasarkan degree of freedom. RMSEA $=0.068 \leq 0.08$

Dari Tabel 5.1 terlihat bahwa GFI = 0.978 mendekati 1, AGFI $=0.933$ mendekati 1, dan CMIN/df $=1.699<2.00$. Dapat dikatakan kriteria Goodness of Fit untuk model terpenuhi dan hasilnya sudah sesuai dan sangat baik.

Dari hasil analisis faktor, jika dilihat pada Tabel 5.1 Hasil SEM, didapatkan bahwa peubah yang paling dominan adalah peubah q2 (peningkatan bisnis ritel disebabkan oleh peningkatan produk konsumen makanan dan minuman), diikuti dengan peubah q3 (peningkatan bisnis ritel disebabkan oleh peningkatan produk konsumen elektronik), q4 (peningkatan bisnis ritel disebabkan oleh peningkatan populasi Indonesia), q5 (peningkatan bisnis ritel disebabkan oleh peningkatan toko ritel di Indonesia), dan terakhir adalah q1 (peningkatan bisnis ritel disebabkan oleh peningkatan produk konsumen rumah tangga).

Dari faktor-faktor tersebut yang paling dominan adalah $\mathrm{q} 2=1.19, \mathrm{q} 3=1.27$, $\mathrm{q} 4=1.10$, dan q5 $=1.22$, karena mempunyai Eigenvalue $>1$.

Bila di bahas satu-persatu, maka faktor yang paling dominan adalah peubah q2 (peningkatan bisnis ritel disebabkan oleh peningkatan produk konsumen makanan dan minuman), dan menurut BMI Research Q4 2016: 'Produk makanan dan minuman Indonesia akan mengalami pertumbuhan dan mengembangkan industri ritel dan industri grosir".

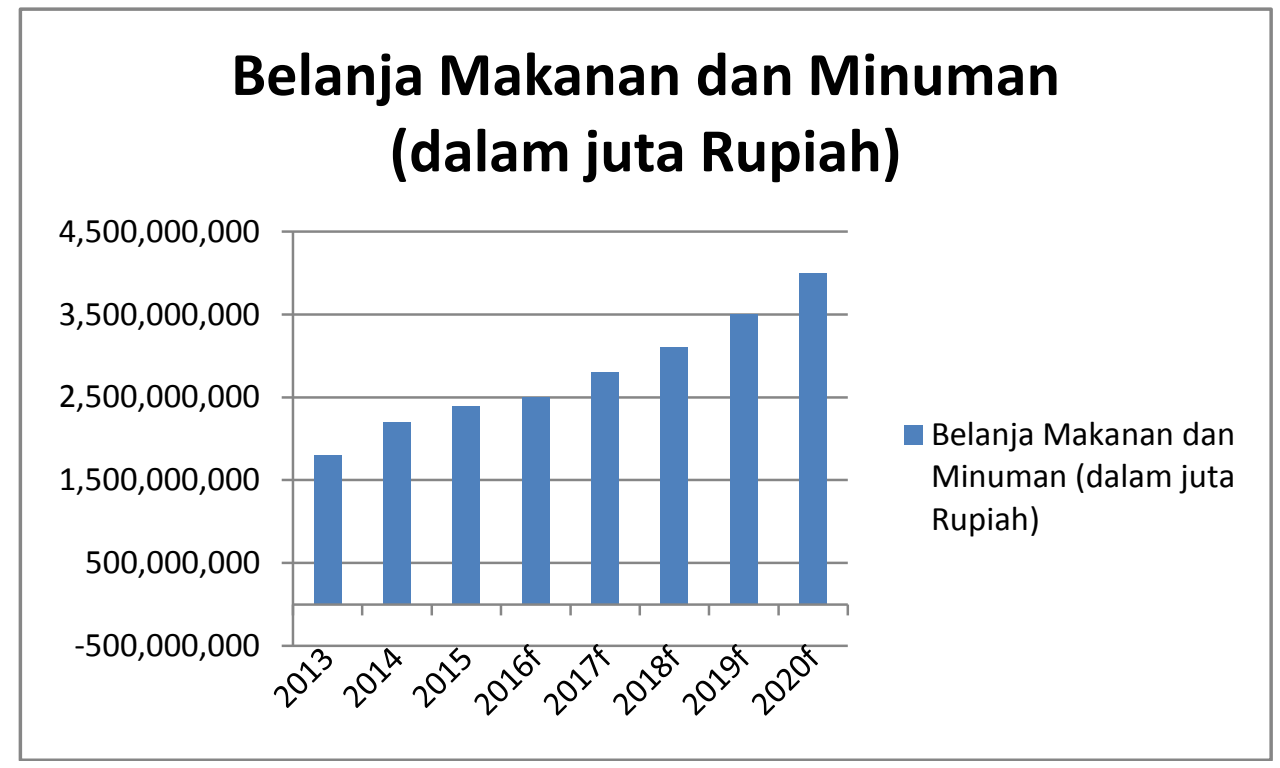

Sumber: BMI Research Q4 2016

Gambar 2. Belanja Makanan dan Minuman (2013-2020)

Menurut BMI Research Q4 2016, berdasarkan periode peramalan sampai 2020, diharapkan pertumbuhan konsumsi makanan dan minuman di Indonesia akan terus berlanjut disebabkan pula oleh pertumbuhan ekonomi dan juga pertumbuhan penghasilan per kapita. Antara 2016 sampai 2020, diramalkan akan ada pertumbuhan sekitar $10.5 \%$ dalam penjualan makanan di ritel. Industri makanan dan minuman di Indonesia mempunyai:

- Kekuatan, diantaranya adalah besarnya populasi Indonesia, pertumbuhan ekonomi dan juga pertumbuhan penghasilan per kapita masyarakat Indonesia kelas bawah yang sebagian besar sudah berubah menjadi masyarakat dengan penghasilan kelas menengah terus 
meningkat. Dasar inilah yang membuat para investor tertarik untuk berinvestasi di sektor industri makanan dan minuman di Indonesia. Hal ini dibuktikan dengan banyaknya penanaman langsung modal asing (foreign direct investment) di industri makanan dan minuman yang diproduksi dengan cara diproses, dan hal ini meyebabkan perkembangan indutri makanan dan minuman yang sangat pesat dalam beberapa tahun terakhir.

- Kelemahan, di antaranya intoleransi pada minuman yang mengandung alkohol berpengaruh terhadap perkembangan indutri minuman beralkohol yang sebenarnya mempunyai potensi yang masih besar.

- Peluang, di antaranya perkembangan ekonomi dan kenaikan pendapatan masyarakat menciptakan peluang yang sangat kuat di sektor bisnis makanan dan minuman. Pertumbuhan dan banyaknya permintaan produksi makanan halal menciptakan peluang yang sangat unik untuk memproduksi dan mengekspor ke negara yang menginginkan makanan halal.

Ancaman, di antaranya meningkatnya persaingan ketat di sektor bisnis minuman bersoda (carbonated soft drinks) akan memengaruhi dalam keuntungan penjualan minumam bersoda. Regulasi pelarangan penjualan minuman bir yang mengandung alkohol di toko ritel kecil sejak April 2015 sangat memengaruhi perkembangan di sektor industri minuman beralkohol.

Peningkatan pendapatan akan mendorong munculnya kelas menengah yang relatif makmur di daerah perkotaan, karena diharapkan akan terjadi peningkatan pendapatan antara USD 10.000 sampai USD 25.000 per tahun. Bagi perusahaan makanan dan minuman, mereka melihat peluang yang kuat untuk membidik kelompok konsumen ini, dengan memperluas tawaran produk premium dan inovatif. Selain itu, sektor MGR (Mass Grocery Retail) merupakan kawasan yang paling berkembang di perkotaan, terutama di provinsi Jakarta dan Jawa Tengah. Berfokus pada area ini, perusahaan makanan dan minuman akan lebih mudah untuk melakukan perluasan jaringan distribusi.

Diperkirakan penjualan makanan utama (dalam mata uang lokal) meningkat sebesar $9,6 \%$ pada tahun 2016, didukung oleh kenaikan pendapatan dan pertumbuhan ekonomi serta kedatangan wisatawan yang kuat. Diperkirakan pertumbuhan konsumsi makanan Indonesia secara keseluruhan sangat kuat, yang telah dan akan terus didukung oleh pertumbuhan ekonomi yang kuat di negara ini dengan kenaikan pendapatan per kapita yang sepadan. Antara 2016 dan 2020, diramalkan tingkat pertumbuhan tahunan gabungan (Compound Annual Growth Rate) sebesar 10,5\% untuk penjualan makanan utama.

$$
\text { Selain itu }
$$

menurut

http://www.kemlu.go.id/id/kebijakan/asean/ Pages/Masyarakat-Ekonomi-ASEAN-

(MEA).aspx, Masyarakat Ekonomi ASEAN (ASEAN Economic Community/AEC) dibentuk untuk mewujudkan integrasi ekonomi ASEAN, yakni tercapainya wilayah ASEAN yang aman dengan tingkat dinamika pembangunan yang lebih tinggi dan terintegrasi, pengentasan masyarakat ASEAN dari kemiskinan, serta pertumbuhan ekonomi untuk mencapai kemakmuran yang merata dan berkelanjutan. Untuk itu MEA memiliki empat karakterisik utama, yaitu pasar dan pangkalan produksi tunggal, kawasan ekonomi yang berdaya saing tinggi, dan kawasan dengan pembangunan ekonomi yang merata, serta kawasan yang terintegrasi penuh dengan ekonomi global.

Faktor kedua yang paling dominan adalah peubah q3 (peningkatan bisnis ritel disebabkan oleh peningkatan produk konsumen elektronik). Menurut $B M I$ Research Q4 2016: "karena penguatan mata uang rupiah dan meningkatnya belanja produk elektronik, maka diharapkan akan ada pertumbuhan $9.7 \%$ pada tahun $2016-$ 2020 di Indonesia". Penjualan 3 kategori, yaitu computer hardware, USD $4.5 \mathrm{bn}$ (2016) menjadi USD 7.6bn (2020), 
pertumbuhan $10.2 \%$ selama periode 2016 2020. Penjualan audio visual, USD 2.1 bn (2016) menjadi USD 2.8 bn (2020), pertumbuhan $7.6 \%$ selama periode 2016 -
2020. Dan penjualan smartphone dan handset USD 7.2 bn (2016) menjadi USD 10.5 bn (2020), pertumbuhan $1 \%$ selama periode $2016-2020$.

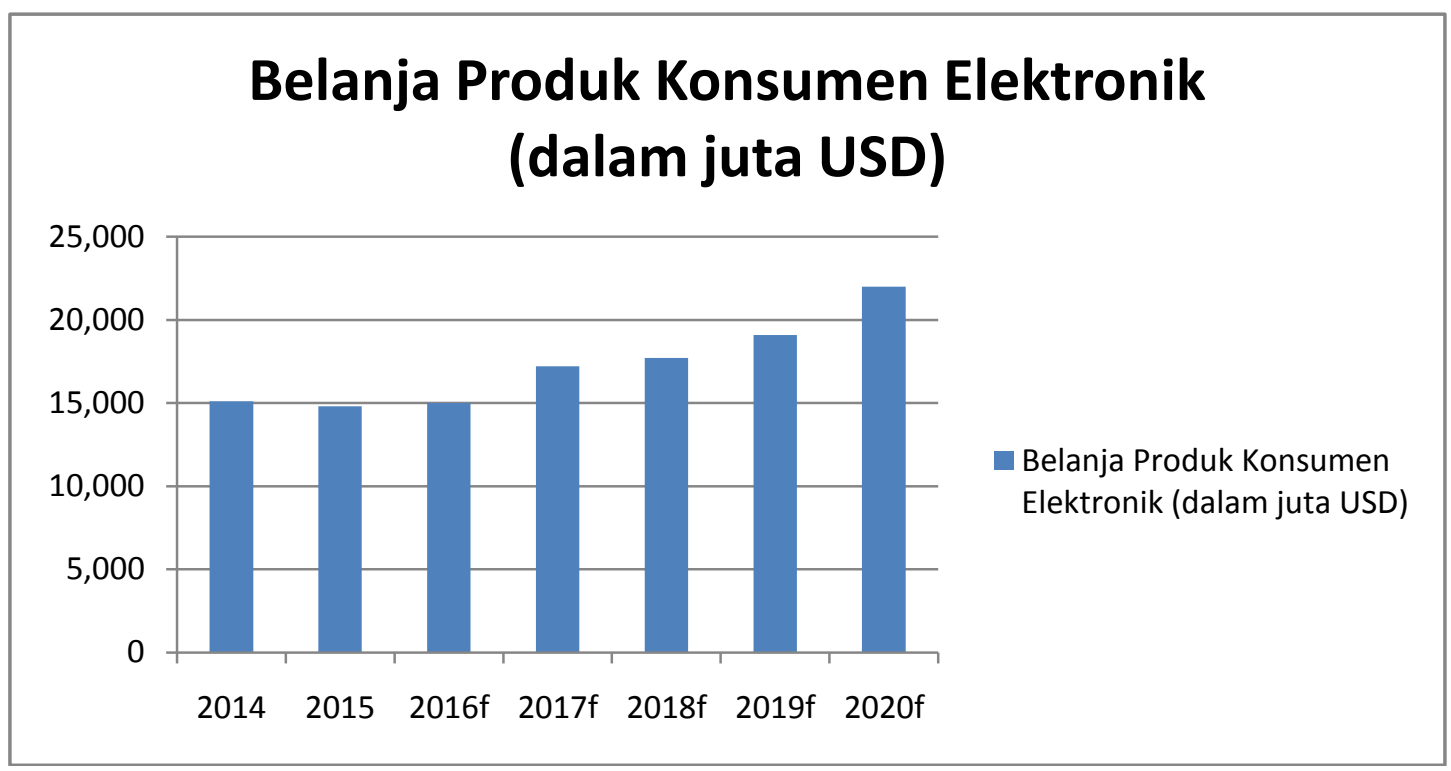

Sumber: BMI Research Q4 2016

Gambar 3. Belanja Produk Konsumen Elektronik (2014 - 2020)

Menurut BMI Research Q4 2016, belanja perangkat elektronik konsumen Indonesia diperkirakan akan mencatat pertumbuhan yang kuat pada CAGR sebesar 9,7\% pada tahun 2016 - 2020. Pertumbuhan ekonomi yang kuat, ditambah apresiasi rupiah terhadap dolar untuk 2018-2020, akan mendorong pertumbuhan karena produk konsumen elektronik dan produk konsumen rumah tangga akan memperoleh daya beli tambahan yang signifikan, karena tumbuhnya pendatang baru di kelas menengah di Indonesia yang semakin makmur. Terdapat perbedaan permintaaan akan produk elektronik, yang masih didominasi oleh konsumen di beberapa kota besar yang tingkat pendapatannya lebih besar, dan logistiknya lebih mudah dikembangkan, dibandingkan kota kecil. Sebagai contoh pemasok LG melaporkan bahwa Jakarta menyumbang penjualan TV yang paling besar, sebanyak $50 \%$ dari penjualan, disusul dengan Surabaya sebesar $15 \%$ dari penjualan. Akan tetapi ada kecenderungan terjadi pertumbuhan yang nyata pada beberapa daerah dengan pendapatan yang lebih rendah, terutama untuk penjualan smartphone di beberapa konsumen di kota kota di Indonesia. Industri elektronik di Indonesia mempunyai:

- Kekuatan, adanya kenaikan tingkat pendapatan masyarakat Indonesia pada umumnya yang mendorong untuk membeli hi-tech produk seperti smartphone dan komputer. Walaupun di beberapa daerah masih ada yang tingkat pendapatannya rendah, akan tetapi pertumbuhan populasi di kota kota di Indonesia membantu dalam pertumbuhan penjualan elektronik di Indonesia secara signifikan.

- Kelemahan, pajak impor produk elektronik masih terlalu besar dan pemberlakuan persyaratan konten lokal $40 \%$ untuk smartphone $4 \mathrm{G}$ untuk produksi lokal, infra struktur yang masih harus diperbaiki seperti 
jaringan Internet, perkembangan gerai ritel di daerah, perkembangan jalan yang baik untuk transportasi yang menyebabkan kesulitan dalam melakukan distribusi, kurangnya pasokan listrik di kota-kota kecil.

- Peluang, pertumbuhan penjualan smartphone yang sangat cepat baik di segmen masyarakat menengah mau pun bawah, yang merupakan sumbangan terbesar dalam pertumbuhan penjualan produk elektronik. Ada kecenderungan masyarakat Indonesia untuk mengganti TV model lama dengan TV LCD dan TV plasma, seiring dengan perkembangan teknologi digital. Ada kecenderungan perusahaan dan institusi pendidikan untuk mempunyai komputer dan laptop serta perangkat LCD untuk kelangsungan bisnisnya ke arah yang lebih baik, yang juga merupakan pemicu penjualan komputer, laptop dan perangkat LCD.

- Ancaman, adanya peraturan pemerintah yang mengharuskan untuk memproduksi di Indonesia, bila perusahaan asing ingin memasarkan sendiri produk elektroniknya di Indonesia. Hal ini berpotensi menaikkan biaya produksi sebesar 50\% dibandingkan negara berkembang lainnya misalnya China.

Prospek jangka panjang yang positif didasarkan pada potensi tingkat pendapatan yang meningkat secara cepat di Indonesia. Inovasi produk dan penurunan harga perangkat di ketiga kategori segmen konsumen elektronik (computer hardware, audio visual, smartphone dan handset), adalah hasil yang dicapai oleh pemasok selama ini. Hal ini akan memungkinkan pertumbuhan permintaan yang akan mengungguli tingkat pertumbuhan yang dicapai oleh pasar yang sedang berkembang pada saat ini.

Profil pendapatan rumah tangga Indonesia akan meningkat secara signifikan di tahun 2016 - 2020. Pada tahun 2020, BMI memperkirakan jumlah penghasilan rumah tangga USD 5.000/tahun, hampir separuh dari total populasi, sebuah perkembangan yang akan memperluas pasar. Juga ada perkembangan kelas menengah yang meluas, dengan jumlah penghasilan rumah tangga USD 10.000+/tahun, diperkirakan meningkat hampir 18,8 juta penduduk Indonesia. Hal ini yang memungkinkan untuk membidik penjualan perangkat dalam kategori PC, perangkat TV dan smartphone.

Dari sisi kategori perangkat konsumen elektronik, yang dapat diharapkan meningkat lagi adalah penjualan smartphone, notebook dan tablet yang sudah sangat unggul penjualannya dalam jangka menengah. Momentum pertumbuhan unit diharapkan dapat dipertahankan dan berkembang dalam jangka panjang ke depan.

Penjualan handset ponsel menyusul penjualan perangkat keras komputer dan menjadi kategori perangkat terbesar di tahun 2014, juga pada tahun 2015. Belanja handset menyumbang $49,4 \%$ dari total penjualan handset, setara dengan nilai USD 6,90 miliar.

Penjualan pasar handset di Indonesia diperkirakan tumbuh pada tingkat pertumbuhan tahunan gabungan adalah sebesar 10\% menjadi USD 10,5 miliar pada tahun 2020. Pasar perangkat keras komputer diperkirakan akan mengungguli penjualan smartphone dalam jangka menengah, karena meledaknya penjualan smartphone mulai berkurang. Pengeluaran untuk pembelian perangkat keras komputer sebesar 35,8\% dari total belanja di ketiga kategori segmen konsumen elektronik (computer hardware, audio visual, smartphone dan handset) pada tahun 2015, dapat dipastikan akan meningkat menjadi 36,3\% di tahun 2020. Perangkat audio visual menyumbang sebagian kecil belanja konsumen elektronik pada tahun 2015 sebesar 14,7\% dari total permintaan. Dalam jangka waktu ke depan, pertumbuhan dapat terjaga dengan baik dengan peluncuran siaran TV digital secara bertahap di kota-kota besar di Indonesia, yang mendorong penjualan TV digital. Pasar diperkirakan akan tumbuh menjadi USD 2,8 miliar pada 2020, meningkat $7,6 \%$ dari tahun 2016 ke tahun 2020. 
Faktor ketiga bagi peningkatan bisnis ritel di Indonesia adalah peningkatan populasi Indonesia yang sedemikian pesat. Saat ini jumlah penduduk Indonesia mencapai 252 juta orang. Permasalahan kependudukan ini menuntut terpenuhinya kebutuhan makanan, sandang, kesehatan, pendidikan, hingga lapangan kerja.

Faktor ke empat dalam peningkatan bisnis ritel di Indonesia adalah peningkatan toko ritel di seluruh pelosok Indonesia. Bila dilihat dari sisi makro ekonomi, pertumbuhan PDB riil diperkirakan rata-rata $6,0 \%$ per tahun 2017 - 2020, dengan perkiraan pertumbuhan konsumsi riil pada rata-rata tahunan $5,5 \%$.

\section{SIMPULAN DAN SARAN}

\section{Simpulan}

Penulis berkesimpulan bahwa faktor yang paling dominan bagi peningkatan bisnis ritel di Indonesia adalah faktor peningkatan produk konsumen makanan dan minuman. Diperkirakan pertumbuhan konsumsi makanan Indonesia secara keseluruhan sangat kuat, yang telah dan akan terus didukung oleh pertumbuhan ekonomi yang kuat di negara ini dengan kenaikan pendapatan per kapita yang sepadan. Antara 2016 dan 2020, diramalkan tingkat pertumbuhan tahunan gabungan (Compound Annual Growth Rate) sebesar $10,5 \%$ untuk penjualan makanan utama. Sektor makanan Indonesia sudah menarik investasi dari multinasional seperti Nestle, dan pelaku industri lokal seperti Indofood, karena mereka berupaya untuk mendapatkan prospek pertumbuhan yang menarik. Kegiatan ekspansif ini di kalangan pemain industri akan terus bergerak dinamis dan lebih besar lagi untuk menghasilkan kemajuan dalam industri makanan. Peningkatan pendapatan akan mendorong munculnya kelas menengah yang relatif makmur di daerah perkotaan, karena diharapkan akan terjadi peningkatan pendapatan antara USD 10.000 sampai USD 25.000 per tahun. Bagi perusahaan makanan dan minuman, mereka melihat peluang yang kuat untuk membidik kelompok konsumen ini, dengan memperluas penawaran produk premium dan inovatif. Selain itu, sektor
MGR (Mass Grocery Retail) merupakan kawasan yang paling berkembang di perkotaan, terutama di provinsi Jakarta dan pulau Jawa. Berfokus pada area ini, perusahaan makanan dan minuman akan lebih mudah untuk melakukan perluasan jaringan distribusi.

Faktor kedua bagi peningkatan bisnis ritel di Indonesia adalah faktor peningkatan belanja produk konsumen elektronik. Timbulnya kecenderungan di masyarakat untuk pemakaian komputer, smartphone dan kecenderungan masyarakat di kota kota besar untuk mengganti perangkat televisinya dengan perangkat televisi digital yang baru, yang disebabkan oleh banyaknya penawaran siaran TV digital dan jaringan Internet WiFi dalam satu paket yang selain berguna untuk melihat acara TV, juga menunjang pekerjaan yang memakai komputer, sedangkan signal WiFi digital sangat diperlukan bagi beroperasinya smartphone. Dalam jangka waktu ke depan, pertumbuhan dapat terjaga dengan baik dengan peluncuran siaran TV digital secara bertahap di kota-kota besar di Indonesia, yang mendorong penjualan TV digital. Pasar diperkirakan akan tumbuh menjadi USD 2,8 miliar pada 2020, meningkat 7,6\% (CAGR) dari tahun 2016 ke tahun 2020. Menteri perdagangan Enggartiasto Lukita menyatakan Indonesia bakal menjadi kekuatan penting dalam ekonomi digital dunia. Hal ini seiring dengan perkembangan sektor dagang-el. (e-commerce)_di dalam negeri dan upaya pemerintah menyusun peta jalan (roadmap) sektor tersebut . Enggar mengungkapkan, saat ini total nilai dagangel. global pada 2015 mencapai USD 16,6 triliun. Angka ini berasal dari business to business (B2B) sebesar USD15 triliun dan business to consumer (B2C) sebesar USD1,6 triliun. Menurut Moody Analitics \& Visa, nilai transaksi dagang-el. di Indonesia pada 2015 mencapai Rp 150 triliun. Pada 2016 diperkirakan akan mencapai USD 20 miliar atau sekitar Rp 250 triliun. Menurut Enggartiasto Lukita, diharapkan jumlah transaksi terus meningkat menjadi USD 130 miliar di 2020, di Gedung Bina Graha, Jakarta, Senin (31/10/2016). (http://bisnis.liputan6.com/read/2639692/tra 
nsaksi-e-commerce-ri-ditargetkan-capai-us130-miliar-di-2020)

Faktor ketiga bagi peningkatan bisnis ritel di Indonesia adalah peningkatan populasi Indonesia yang sedemikain pesat. Presiden Jokowi mengatakan saat ini jumlah penduduk Indonesia mencapai 252 juta orang. Permasalahan kependudukan ini menuntut terpenuhinya kebutuhan makanan, sandang, kesehatan, pendidikan, hingga lapangan kerja. "Laju penduduk Indonesia 1,3 persen, artinya setiap tahun ada tambahan 3 juta orang," katanya di Desa Mertasinga, Cirebon, Kamis, 14 Januari 2016.

(https://m.tempo.co/read/news/2016/01/14/1

73736151/tiap-tahun-penduduk-indonesiabertambah-3-juta-orang).

Faktor ke empat dalam peningkatan bisnis ritel di Indonesia adalah peningkatan toko ritel di seluruh pelosok Indonesia. Asosiasi Pengusaha Ritel Indonesia (Aprindo) mengungkapkan, pada tahun 2016, terjadi peningkatan penjualan sekitar 10 persen pada industri ritel nasional. Peningkatan ini terjadi sejalan dengan perbaikan perekonomian Indonesia pada tahun ini. Ketua Umum Aprindo Roy N Mandey mengatakan, total nilai penjualan ritel pada 2015 sebesar Rp 181 triliun, sedangkan pada tahun ini diprediksi akan tembus Rp 200 triliun. "Tahun 2016 ini kami optimistis bisa menutup di double digit, yaitu 10 persen untuk peningkatan penjualan toko ritel kami. Tahun lalu dengan tingkat pertumbuhan ekonomi 4,7 persen, kami menutup dengan angka 8 persen. Kami harapkan, bisa menutup di angka 10 persen pada 2016 ini," ujar Roy saat konferensi pers Aprindo di Kawasan Kuningan, Jakarta, Rabu (28/12/2016). Untuk tahun 2017, pihaknya yakin pertumbuhan penjualan di industri ritel akan melebihi pertumbuhan pada tahun ini, seiring dengan prediksi pertumbuhan ekonomi pada 2017 yang mencapai 5,4 persen. "Kami optimistis, pada 2017, berharap minimal sama 10 persen.

Bila dilihat dari sisi makro ekonomi, pertumbuhan PDB riil diperkirakan rata-rata $6,0 \%$ per tahun 2017 - 2020, dengan perkiraan pertumbuhan konsumsi riil pada rata-rata tahunan 5,5\%. Apresiasi rupiah terhadap US dolar juga akan meningkatkan keterjangkauan pembelian perangkat elektronik di pasar. Diperkirakan rupiah akan menguat dari rata-rata $\mathrm{Rp} 13.800$ / USD pada 2017 menjadi Rp 12.900 / USD pada tahun 2020 - sebuah kecenderungan yang sangat berbeda dengan kecenderungan 2013 - 2015 ketika daya beli masyarakat Indonesia di pasar global yaitu untuk produk impor, sangat menurun. Profil pendapatan rumah tangga Indonesia akan meningkat secara signifikan di tahun 2016 - 2020. Pada tahun 2020, BMI memperkirakan jumlah penghasilan rumah tangga USD 5.000/tahun, hampir separuh dari total populasi, sebuah perkembangan yang akan memperluas pasar. Juga ada perkembangan kelas menengah yang meluas, dengan jumlah penghasilan rumah tangga USD10.000+/tahun.

\section{Saran}

Saran dari penulis adalah agar industri ritel di Indonesia lebih memperhatikan pertumbuhan bisnis produk konsumsi makanan dan minuman sebagai bisnis unggulan yang utama. Selain itu juga harus memerhatikan bisnis produk konsumsi elektronik sebagai bisnis unggulan yang kedua. Dan sesuai dengan peningkatan yang pesat dari populasi Indonesia maka disarankan agar para pebisnis ritel juga membuka gerai ritel nya di seluruh pelosok tanah air yang belum dijangkau gerai ritel. Prediksi pertumbuhan ekonomi Indonesia yang bagus di masa depan juga sangat menunjang pertumbuhan gerai ritel dengan sangat pesat, dan masih sangat dibutuhkan keberadaannya. Disarankan pembukaan gerai ritel lebih menyebar ke seluruh daerah terpencil di Indonesia yang masih sedikit jumlah gerai ritel nya.

\section{DAFTAR PUSTAKA}

Aaker, Kumar, Day. 2007. Maketing Research. $9^{\text {th }}$ Ed. John Wiley \& Sons, Inc, New York.

Ashis Mishra, Javeed Ansari. 2013. A conceptual model for retail productivity. US retail executives' perspectives on the future of retailing. 
Berman, Evans. 2013. Retail Management, A Strategic Approach, International Edition. $12^{\text {th }}$ Ed. Pearson Education, Inc., USA.

Business Monitor International, Indonesia Consumer Electronics Report, Q4, 2016, www.bmiresearch.com

Business Monitor International, Indonesia Food \& Drink Report, Q4, 2016, www.bmiresearch.com

Dahlan, U. 2014. Panduan Lengkap Structural Equation Modeling $\left(1^{\text {st }}\right.$ ed.). Lentera Ilmu, Semarang.

DeHerder, Blatt. 2011. Shopper Intimacy: A Practical Guide to Leveraging Marketing Intelligence to Drive Retail Success. $1^{\text {st }}$ Ed. Pearson Education, Inc., USA.

Diamond, Pintel. 2014. Retail Buying, New International Edition. $9^{\text {th }}$ Ed. Pearson Education, Inc., USA.

Eunah Yoh, LuAnn R. Gaskill. 1998. US retail executives' perspectives on the future of retailing.

Fam Kim-Shyan, Run Ernest Cyril de, Shukla Paurav. 2013. Emerging trends for marketing in Asia.

Goworek, McGoldrick. 2015. Retail Marketing Management: Principles and Practice. $1^{\text {st }}$ Ed. Pearson Education, Inc., USA.

Hair, Black, Babin, Anderson. 2010. Multivariate Data Analysis. $7^{\text {th }}$ Ed. Pearson Education, Inc., Upper Saddle River, New Jersey.

Jogiyanto, HM. 2011. Konsep dan Aplikasi Structural Equation Modeling Berbasis Varian Dalam Penelitian Bisnis. $1^{\text {st }}$ Ed. STIM YKPN, Yogyakarta.
Levy, Weitz. 2013. Retailing Management. $8^{\text {th }}$ Ed. McGraw-Hill/Irwin, New York.

Malhotra, N.K. 2010. Marketing Research, An Applied Orientation. $6^{\text {th }}$ Ed. Pearson Education, Inc., Upper Saddle River, New Jersey.

Lisa Maharajh, Jeanne Heitmeyer. 2006. Factors that impact United States retailers' expansion into the international marketplace.

Polly Chan, Carol Finnegan, Brenda Sternquist. 2011. Country and firm level factors in international retail expansion.

Sarjono, H., Julianita, W. 2015. Structural Equation Modeling (SEM) Sebuah Pengantar Aplikasi Untuk Penelitian Binis. Salemba Empat, Jakarta.

Sekaran, Uma. 2003. Research Methods for Business - A Skill Building Approach. $4^{\text {th }}$ Ed. John Wiley \& Sons, USA

Sumarni, M., Wahyuni, S. 2006. Metodologi Penelitian Bisnis. $1^{\text {st }}$ Ed. ANDI, Yogyakarta.

Wantao Yu, Ramakrishnan Ramanathan. 2012. Effects of business environment on international retail operations: case study evidence from China.

Wijaya, T. 2013. Analisis Structural Equation Modeling Menggunakan AMOS. $5^{\text {th }}$ Ed. Universitas Atma Jaya, Yogyakarta.

(https://m.tempo.co/read/news/2016/01/14/1 73736151/tiap-tahun-pendudukindonesia-bertambah-3-juta-orang.

http://www.kemlu.go.id/id/kebijakan/asean/ Pages/Masyarakat-Ekonomi-

ASEAN-(MEA).aspx 